\title{
Liver Resection for Giant Hepatic Cavernous Hemangioma
}

\author{
Puneet Kumar ${ }^{1, *}$, Satyendra K Tiwary ${ }^{1}$, Priyesh Shukla ${ }^{2}$, Ashish Verma ${ }^{3}$, A K Khanna ${ }^{1}$
}

1. Department of Surgery, Institute of Medical Sciences,Banaras Hindu University, Varanasi, India

2. Department of Surgery,Govt. Medical College, Azamgarh, India

3. Department of Radiodiagnosis, Institute of Medical Sciences,Banaras Hindu University, Varanasi, India

\section{* Corresponding Author:}

Puneet Kumar, MD

Department of Surgery,Institute of Medical Sciences, Banaras Hindu University,

Varanasi, India

Tel: + 919415304896

Fax: + 915422367568

Email: puneetimsbhu@gmail.com

Received: 25 Jul. 2020

Accepted: 19 Jun. 2021

\section{ABSTRACT}

Liver hemangiomas are common. Giant liver hemangiomas are rare and symptomatic patients require treatment. Surgery is the curative procedure. Other options such as intra-arterial embolization may be used to decrease the volume and bleeding of these lesions.

Three cases of giant liver hemangioma were treated with liver resection, one with left lateral hepatectomy and two with right lateral hepatectomy. All patients had made an uneventful recovery with no recurrence at 3-year follow-up.

Most hemangiomas are small, asymptomatic, and do not require any treatment. Liver resection is a safe and effective treatment for giant hemangiomas.

KEYWORDS:

Liver, Hemangioma, Resection, Hepatectomy

Please cite this paper as:

Kumar P, Tiwary SK, Shukla P, Verma A, Khanna AK. Liver Resection for Giant Hepatic Cavernous Hemangioma. Middle East J Dig Dis 2021;13:268-272. doi: 10.34172/ mejdd.2021.235.

INTRODUCTION

Cavernous hemangioma is the most common benign tumor of the liver, with an estimated prevalence of $0.4-20 \% .^{1}$ These are diagnosed at any age but commonly encountered in women in the third to fifth decade of life. Lesions are usually small and are asymptomatic. They are mostly discovered as an incidentalfindings during imaging studies. Giant hepatic hemangioma designated for lesions with diameter $>10 \mathrm{~cm} .{ }^{2}$ Large lesions cause abdominal discomfort, pain, and coagulation disorder. It may also present with hemorrhage or rupture. There are various treatment options available for giant liver hemangiomas. Surgical excision is the most effective and curative treatment. The other treatment options are arterial ligation, transcatheter arterial embolization (TAE), radiotherapy, radiofrequency ablation, and liver transplantation. ${ }^{3}$ We report three cases of giant hemangioma of the liver treated with liver resection with no morbidity.

\section{CASE REPORT}

Three patients with giant liver hemangiomas presented between March 2016 to March 2017 were included. The detailed summaries of the cases 
are described in table 1. Ultrasound and contrast-enhanced computed tomography (CT) were performed in all cases, which confirmed the presence of giant liver hemangioma. In our series, one case had a lesion in the left lateral lobe while the other two had in the right lobe of the liver. Upper gastrointestinal endoscopy was performed in all cases, as they presented with abdominal pain and dyspepsia, to exclude the gastrointestinal cause of the pain. The decision of the surgical procedure was made on the basis of the size and site of the lesion, its relationship with the vascular and biliary structure, and also considering the remnant liver volume.

In all three cases, the right subcostal incision was used. The central venous pressure (CVP) was kept low during the surgical procedure. The feeding hepatic artery was controlled with bulldog clamp. The inflow control was taken with Pringle maneuver in left lateral hepatectomy while ligating the right portal vein in other two cases planned for right hepatectomy. The left lateral hepatectomy was performed by dividing the hepatic parenchyma and ligating the pedicle. In other patients, the line of demarcation appeared following the ligation of the right portal vein, the outflow control was taken by ligating the right hepatic vein, and the hepatic parenchymal transaction was performed. Bleeding on the cut surface of the liver was controlled with suture ligation and electrocautery. The liver surface was also checked for bile leaks. All three patients made an uneventful recovery and were discharged in the second week after the surgery. Histology in all three cases confirmed cavernous hemangioma. In the follow-up of 3 years, all three patients are asymptomatic, and ultrasonography showed hypertrophied remnant liver with no recurrence of the lesion.

\section{DISCUSSION}

Giant hemangiomas of the liver are rare. Benign lesions are commonly diagnosed in the third to fifth decades of life. ${ }^{2}$ It is common in women with male to female ratio of 1:5.1 Hepatic hemangiomas are usually solitary; however, $10 \%$ of cases have multiple lesions. Liver hemangiomas are classified based on their size as small $(<5 \mathrm{~cm})$, large $(5-10 \mathrm{~cm})$, or giant $(>10 \mathrm{~cm})$. Most of the liver hemangio- mas are small, asymptomatic, and are diagnosed incidentally on imaging studies. ${ }^{3}$ However, large and giant hemangiomas may present with non-specific symptoms such as abdominal discomfort, pain, abdominal fullness, distension, and indigestion. ${ }^{2}$ Rarely, huge liver hemangioma causes compression effect as obstructive jaundice or gastric outlet obstruction. ${ }^{4}$ The other complications such as congestion, hemorrhage, infarction, thrombosis, and spontaneous rupture may be seen. Syndromes such as Kasabach-Merritt syndrome and Bornman-TerblancheBlumgart syndrome (fever and abdominal pain) are rare presentations. Kasabach-Merritt syndrome (consumption coagulopathy) is more common in children than the adults. In this condition, intratumor thrombus consumed a large proportion of coagulation factors presenting as hemolytic anemia, thrombocytopenia, prolonged prothrombin time, and hypofibrinogenemia. ${ }^{5}$

The exact pathogenesis of hepatic hemangioma is unknown. The two theories that exit include dysregulation of angiogenic factors and genetic mutations. It may be associated with overexpression of angiogenic factors like vascular endothelium growth factor, basic fibroblast growth factor, and metalloproteinases or downregulation of few angiogenic inhibitors like metalloproteinase-I. It is reported that endothelial cells of hemangiomas differ from that of hepatic sinusoids in phenotype, morphology, and also in function. In In-vitro studies, hemangioma endothelial cells have shown more angiogenic capacity and abnormal capillary-like structure formation. Studies also showed enlarged endoplasmic reticulum in hemangioma cells.

Histologically, hemangiomas are classified as sclerosing hemangioma, vascular endothelial hemangioma, capillary hemangioma, and cavernous hemangioma, of them, cavernous hemangioma is the most common. ${ }^{6}$ The treatment options for the giant haemangioma include liver resection, enucleation, and embolization. High risk of complications as internal bleeding, growth, and rupture are reported for lesions larger than $10 \mathrm{~cm}$. In our cases, lesions were huge and symptomatic. Liver resection, left lateral hepatectomy in one case, and right hepatectomy in the other two cases were performed with no morbidity. This was the curative procedure, and the patients are asymptomatic at 3 years of follow-up. The enucleation with temporary inflow occlusion was the other surgical procedure that may be used in these patients. Other options like 
Table 1: Summary findings of the patients with liver hemangiomas $(n=3)$

\begin{tabular}{|c|c|c|c|c|c|}
\hline S.no & $\begin{array}{l}\text { Age/ } \\
\text { sex }\end{array}$ & $\begin{array}{l}\text { Presentation/ Ex- } \\
\text { amination finding }\end{array}$ & CT scan finding & $\begin{array}{c}\text { Haemoglobin and } \\
\text { platelet count } \\
\text { (pre-operative) }\end{array}$ & Surgery \\
\hline \multirow[t]{3}{*}{1} & $32 / \mathrm{F}$ & $\begin{array}{l}\text { Pain in epigastric } \\
\text { region / Hepato- } \\
\text { megaly in the left } \\
\text { lobe }\end{array}$ & $\begin{array}{l}\text { A large space-occupying lesion in the left lobe, (A) } \\
\text { Portal venous phase showing peripheral blobs of } \\
\text { contrast filling from the periphery (white arrow) (B) } \\
\text { Arterial phase showing a feeder (black arrow), note } \\
\text { the increased enhancement seen in the portal venous } \\
\text { phase is not noted in the arterial phase proving } \\
\text { centripetal migration (fi gure 1) }\end{array}$ & $\begin{array}{c}11 \mathrm{gm} \% \\
1.81 \mathrm{ac} / \mathrm{mm} 3\end{array}$ & $\begin{array}{l}\text { Left lateral } \\
\text { hepatectomy } \\
\text { (figure 1) }\end{array}$ \\
\hline & $34 / \mathrm{F}$ & $\begin{array}{l}\text { Pain in right upper } \\
\text { abdomen/ Hepato- } \\
\text { megaly right lobe }\end{array}$ & $\begin{array}{l}\text { Non-contrast tomogram of the upper abdomen showing } \\
\text { a mass lesion with a central focus of calcification } \\
\text { (white arrow) in the right lobe of the liver. The portal } \\
\text { venous (B) and delayed (C) phases show progressive } \\
\text { filling of contrast "lakes" from the periphery to the } \\
\text { center (black arrows, figure 2) }\end{array}$ & $\begin{array}{c}10.1 \mathrm{gm} \% \\
2.69 \mathrm{lacs} / \mathrm{mm} 3\end{array}$ & $\begin{array}{l}\text { Right } \\
\text { hepatectomy } \\
\text { (figure 2) }\end{array}$ \\
\hline & $32 / \mathrm{F}$ & $\begin{array}{l}\text { Pain in right } \\
\text { upper abdomen/ } \\
\text { Hepatomegaly in } \\
\text { the right lobe }\end{array}$ & $\begin{array}{l}\text { Contrast-enhanced tomogram of the abdomen } \\
\text { showing large space-occupying lesion in the right } \\
\text { lobe, portal venous phase (A) axial and coronal (B) } \\
\text { reconstructions showing peripheral blobs of contrast } \\
\text { filling from the periphery (white arrow), note the } \\
\text { central hypoattenuating area showing no contrast } \\
\text { uptake (black arrow, figure 3) }\end{array}$ & $\begin{array}{c}11.2 \mathrm{gm} \% \\
2.16 \mathrm{lacs} / \mathrm{mm} 3\end{array}$ & $\begin{array}{l}\text { Right } \\
\text { hepatectomy } \\
\text { (figure 3) }\end{array}$ \\
\hline
\end{tabular}
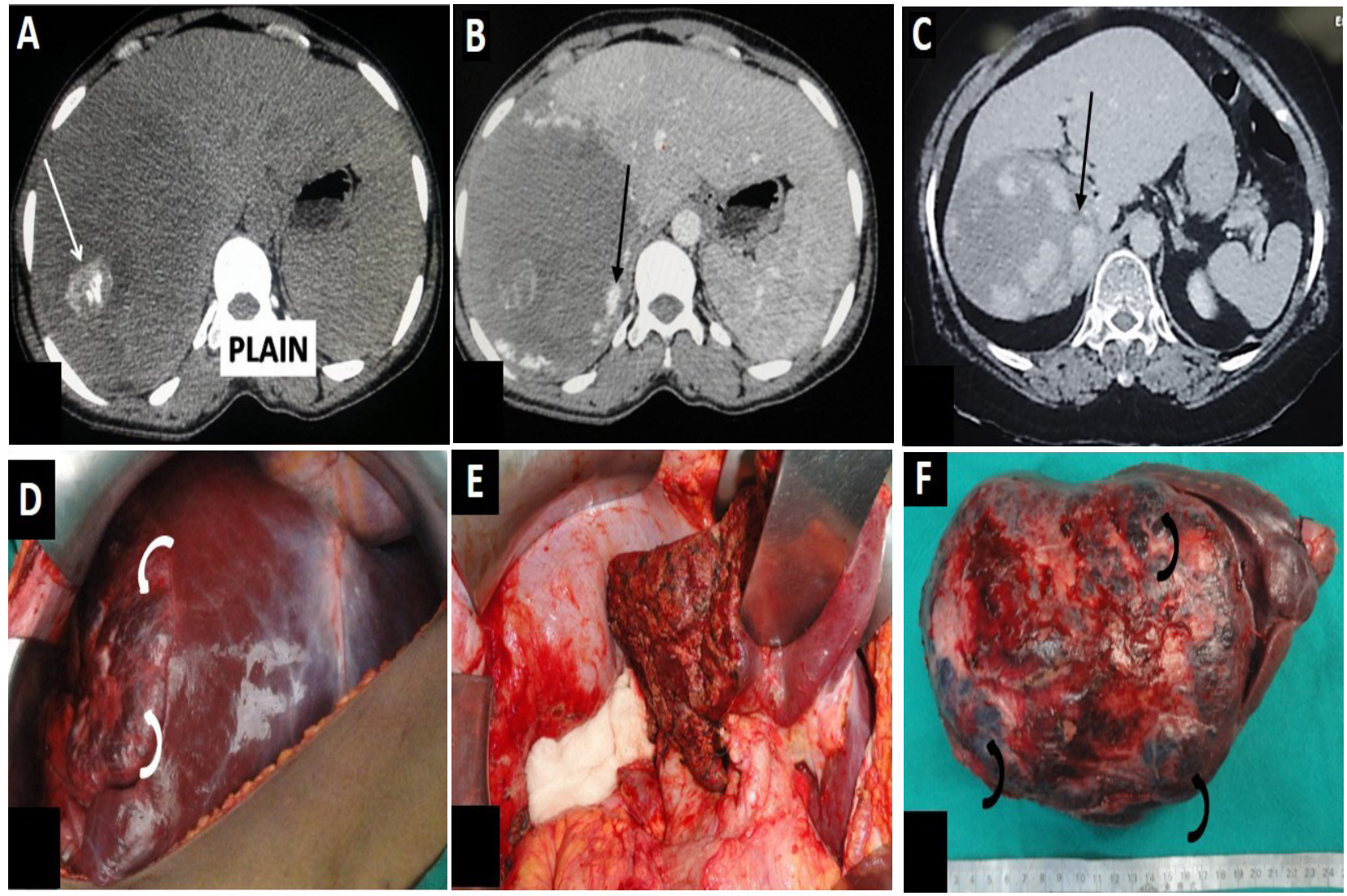

Fig. 1: Contrast-enhanced tomogram of the abdomen showing large space-occupying lesion in the left lobe, (A) Portal venous phase showing peripheral blobs of contrast filling from the periphery (white arrow) (B) Arterial phase showing a feeder (black arrow), note the increased enhancement seen in the portal venous phase is not noted in the arterial phase proving centripetal migration (C). Operative picture showing mass lesion within the liver (curved arrow) (D). Cut surface of the liver after resection (E). Specimen of the left lateral hepatectomy showing lesion with clotted blood-filled spaces. 



Fig. 3: Contrast-enhanced tomogram of the abdomen showing a large space-occupying lesion in the right lobe, portal venous phase (A), axial, and coronal (B) reconstructions showing peripheral blobs of contrast filling from the periphery (white arrow). Note the central hypoattenuating area showing no contrast uptake (black arrow) (C). Operative picture showing mass lesion within the liver (D). Raw cut surface of the liver with long segment IV and pedicle (E) liver with tumor after resection. Note the areas marked on the tomogram by arrows showing corresponding areas on gross specimen also. The central non-enhancing area (black arrow) is seen as a white scar-like area.

transarterial embolization (TAE) may be considered in giant liver hemangiomas. However, the results of TAE are quite variable, and it may sometimes result in a volume increase. TAE may also be done prior to surgical resection, and it decreases lesion volume and intra-operative hemorrhage. ${ }^{7}$

Extremely large lesions $(>20 \mathrm{~cm})$ that occupy the large space in the upper abdomen are difficult to mobilize and may require TAE or preligation of unilateral hepatic artery and portal vein. This would soften the lesion and also decreases its size, making the liver easier to mobilize. It also helps in reducing the bleeding during the surgical procedure. Radiotherapy or liver transplantation is reserved for patients in whom the lesion is not amenable for resection. Radiotherapy is not recommended as the first-line therapy because of treatment-related liver toxicity and also the risk of developing second malignancy in the long term. ${ }^{8}$

In conclusion, most of the small liver hemangiomas are diagnosed incidentally and should be observed by followup and imaging studies. Giant symptomatic hemangiomas should be treated, and surgery is the only curative procedure. Liver resection can easily be performed in giant liver hemangiomas with no morbidity and recurrence.

\section{ETHICAL APPROVAL}

There is nothing to be declared.

\section{CONFLICT OF INTEREST}

The authors declare no conflict of interest related to this work. 

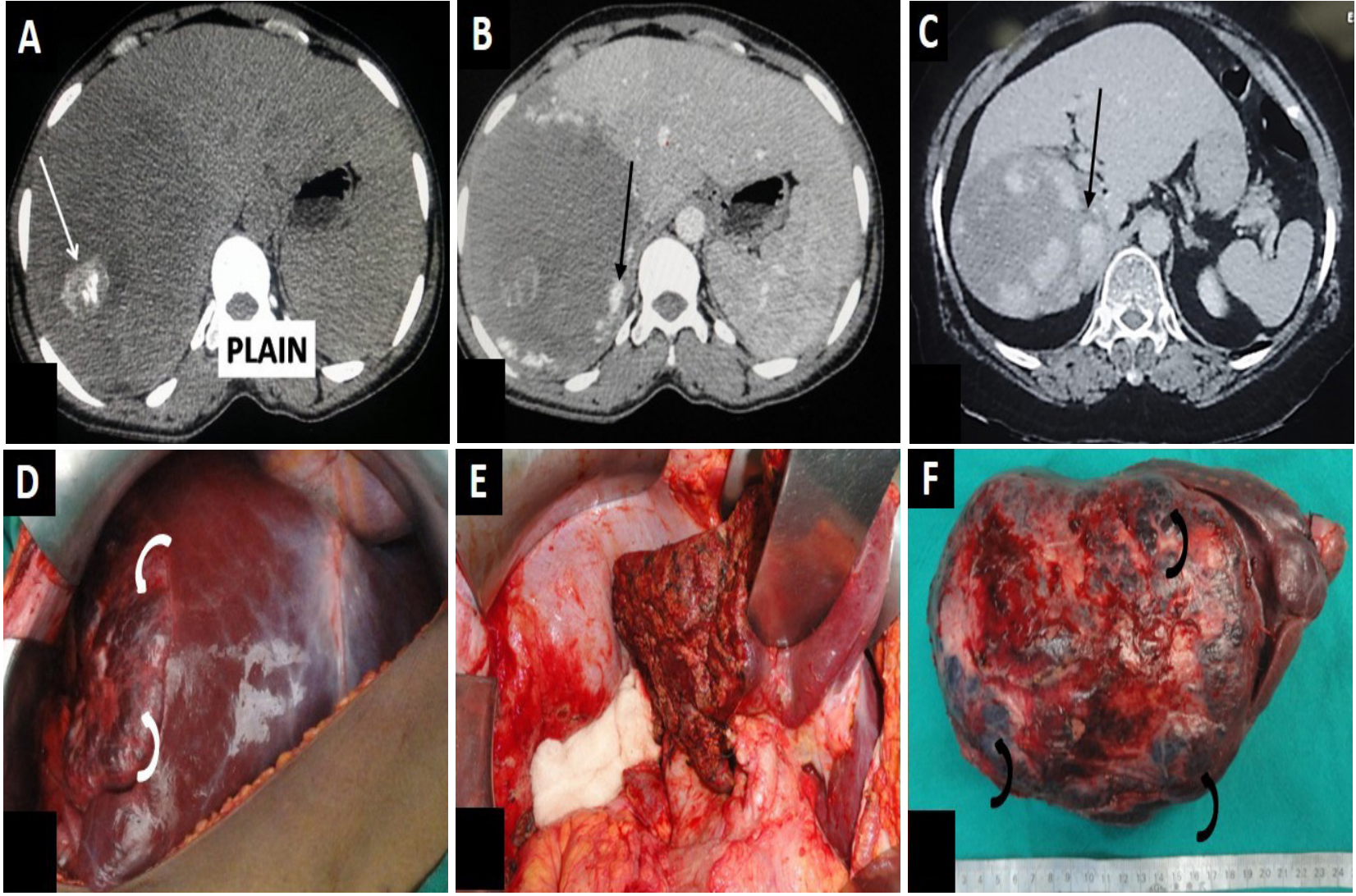

Fig, 2: (A) Non-contrast tomogram of the upper abdomen showing a mass lesion with a central focus of calcification (white arrow) in the right lobe of the liver. The portal venous $(B)$ and delayed $(C)$ phases show progressive filling of contrast "lakes" from periphery to the center (black arrows). Surgical images include the intraoperative exposed liver (D), the cut liver surface (E), and the operative specimen (F), confirm the impression on imaging. Note the peripheral reddish-brown colored areas in panel D (curved white arrows) representing the venous "lakes" in contrast-enhanced tomogram are seen as bluish areas in panel F (curved black arrows) due to thrombosis of blood in the ex-vivo specimen.

\section{REFERENCES}

1. Leon M, Chavez L, Surani S. Hepatic hemangioma: What internists need to know. World J Gastroenterol 2020;26:11-20. doi:10.3748/wjg.v26.i1.11.

2. Di Carlo I, Koshy R, Al Mudares S, Ardiri A, Bertino G, Toro A. Giant cavernous liver hemangiomas: is it the time to change the size categories?. Hepatobiliary Pancreat Dis Int 2016;15:21-9. doi:10.1016/s1499-3872(15)60035-2.

3. Hoekstra LT, Bieze M, Erdogan D, Roelofs JJ, Beuers UH, van Gulik TM. Management of giant liver hemangiomas: an update. Expert Rev Gastroenterol Hepatol 2013;7:263-8. doi:10.1586/egh.13.1.

4. Aydin C, Akbulut S, Kutluturk K, Kahraman A, Kayaalp C, Yilmaz S. Giant hepatic hemangioma presenting as gastric outlet obstruction. Int Surg 2013;98:19-23. doi:10.9738/CC170.1.

5. Yang Z, Tan H, Liu X, Sun Y. Extremely Giant Liver Hemangioma $(50 \mathrm{~cm})$ with Kasabach-Merritt Syndrome. J Gastrointest Surg 2017;21:1748-9. doi:10.1007/s11605-017-3429-7.
6. de Knegt RJ, Potthoff A, Wirth T. Management benigner Lebertumoren [Management of benign liver tumors]. Internist (Berl) 2020;61:140-46. doi:10.1007/s00108019-00736-5.

7. Miura JT, Amini A, Schmocker R, Nichols S, Sukato $\mathrm{D}$, Winslow ER, et al. Surgical management of hepatic hemangiomas: a multi-institutional experience. $H P B$ (Oxford) 2014;16:924-8. doi:10.1111/hpb.12291.

8. Toro A, Mahfouz AE, Ardiri A, Malaguarnera M, Malaguarnera $\mathrm{G}$, Loria $\mathrm{F}$, et al. What is changing in indications and treatment of hepatic hemangiomas. A review. Ann Hepatol 2014;13:327-39. 